\title{
Carpometacarpal Joint
}

National Cancer Institute

\section{Source}

National Cancer Institute. Carpometacarpal/oint. NCI Thesaurus. Code C32265.

The synovial joints between the carpal and metacarpal bones in the hand. 